\title{
Penyuluhan Kesehatan Tentang Latihan Aktivitas Fisik (Stretching) Terhadap Nyeri Sendi Pada Lansia Di Desa Megucilik Kabupaten Cirebon
}

\author{
Supriatin \\ STIKes Cirebon, \\ e-mail: supriatin98@yahoo.co.id
}

\begin{abstract}
ABSTRAK
Tujuan penelitian ini adalah untuk mengetahui pengaruh latihan aktivitas fisik (stretching) terhadap nyeri sendi pada lansia. Metode penelitian quasa eksperimental dengan menggunakan rancangan penelitian Pre-Post Test Design One Group. Sampel adalah lansia yang mengalami nyeri sendi di Desa Megucilik sebanyak 30 responden yang diambil dengan menggunakan teknik purposive sampling. Intensitas nyeri sendi diukur dengan instrument skala nyeri Paint Numeric Rating Scale (PNRS) baik sebelum maupun sesudah dilakukan latihan aktivitas fisik. Uji statistik menggunakan paired $t$ test dengan tingkat kepercayaan 95\% ( $\alpha 0,05)$. Hasil penelitian didapatkan bahwa sebelum dilakukan latihan aktivitas fisik (stretching) tingkat intensitas nyeri ringan $(13,3 \%)$, sedang $(73,3 \%)$, dan berat $(13,3 \%)$, dan sesudah dilakukan latihan aktivitas fisik (stretching) tingkat intensitas nyeri ringan $(86,7 \%)$, sedang $(10,0 \%)$, berat $(3,3 \%)$. Hasil rata-rata uji paired t-test ini adalah 0.833 dan Standar deviasinya 0.379 nilai $\mathrm{p}<0.05$ (0.000). Maka dari hasil uji paired t-test tersebut diketahui bahwa ada pengaruh latihan aktifitas fisik (stretching) terhadap penurunan intensitas nyeri.
\end{abstract}

Kata kunci: Nyeri sendi, Latihan aktivitas fisik, Lansia

\begin{abstract}
The objective of this study was to determine the effect of physical activity exercises (stretching) on joint pain in the elderly. Quasa experimental research methods using research design PrePost Test Design One Group. Samples are older people who experience joint pain in the village Megucilik of 30 respondents taken using a purposive sampling technique. Joint pain intensity was measured by a scale instrument Paint Numeric Rating Scale (PNRS) both before and after exercise to do physical activity. Statistical test using a paired t-test with a confidence level of 95\% (a 0.05). Results showed that prior to physical activity exercises (stretching) the level of pain intensity of mild (13.3\%), moderate (73.3\%), and severe (13.3\%), and after physical activity exercises (stretching) level mild pain intensity (86.7\%), moderate (10.0\%), weight (3.3\%). The average yield of the paired $t$-test is 0833 and 0379 Standard deviation p-value of $<0.05(0.000)$. Thus the test results paired t-test was known that there was an effect of physical activity exercises (stretching) the reduction in pain intensity.
\end{abstract}

Keywords: Joint pain, exercise is physical activity, Elderly 


\section{PENDAHULUAN}

Penetapan usia 65 tahun ke atas sebagai awal masa lanjut usia (lansia) dimulai pada abad ke-19 di Negara jerman (Potter \& Perry, 2009). Proses yang terjadi secara umum pada seluruh spesies secara progresif yang menghasilkan perubahan - perubahan sehingga menyebabkan adanya disfungsi organ dan kegagalan suatu organ atau suatu sistem tubuh tertentu disebut menua. Menua (menjadi tua) merupakan proses menghilangnya kemampuan jaringan secara perlahan-lahan dengan tujuan mempertahankan fungsi normalnya dan memperbaiki diri mengganti sehingga pertahanan terhadap infeksi menjadi berkurang dan kerusakan yang dialami dapat diperbaiki (Darmojo \& Martono, 2006).

Proses menua (aging process) dipengaruhi oleh faktor eksogen dan endogen yang dapat menjadi faktor resiko penyakit degenerative yang bisa dimulai sejak usia muda atau produktif, namun bersifat subklinis (Fatmah, 2010). Aging Process atau proses menua terjadi secara alami dan pasti pada setiap makhluk hidup yaitu tubuh akan kehilangan kemampuan progresif organ, jaringan dan sel-selnya. Berkurangnya kemampuan pertahanan struktur dan fungsi berbagai organ tubuh berkurang. Tubuh juga kurang memberikan reaksi imunitas terhadap invasi mikrooganisme. Ketidakmampuan dan ketergantungan tidak selalu diakibatkan oleh proses penuaan. Meskipun dalam kondisi penyakit kronis, sebagian besar lansia masih bisa mandiri secara fungsional. Terdapat keterkaitan yang erat yang terjadi pada proses penuaan antara aspek fisik dan psikososial (Fatmah, 2010).

Perkembangan Penduduk Lanjut usia (lansia) di Indonesia menarik diamati. Jumlahnya cenderung meningkat dari tahun ke tahun. Hasil laporan Kantor Kementerian Koordinator Kesejahteraan Rakyat (KESRA) adalah usia harapan hidup (UHH) 52,2 tahun 1980 dan jumlah lansia 7.998 .543 orang $(5,45 \%)$, pada tahun 2006 menjadi 19 juta orang $(8,90 \%)$ dan UHH $(66,2$ tahun) mengalami peningkatan. Perkiraan penduduk lansia di Indonesia akan mencapai 23,9 juta atau 9,77\% pada tahun 2010 dan UHH sekitar 67,4 tahun. Pada tahun 2020 perkiraan penduduk lansia di Indonesia mencapai 28,8 juta atau 11,34 \% dengan UHH sekitar 71,1 tahun (Badan Pusat Statistik, 2010).

Perubahan-perubahan fisik, biologis, psikologis dan sosial atau munculnya penyakit degenerative akibat proses penuaan mempengaruhi aspek peningkatan jumlah lansia (Darmojo \& Martono, 2006). Adanya perubahan - perubahan tersebut tidak bersifat patologis, namun lansia lebih rentan terhadap beberapa penyakit (Potter \& Perry, 2009). Salah satunya adanya perubahan yang dialami pada sistem muskuloskeletal dimana lansia mengalami perubahan seiring penuaan seperti penurunan fungsi otot yang berdampak pada serat otot menjadi kecil sehingga berkurangnya kekuatan otot dan massa otot serta massa tulang juga berkurang. Pada lansia yang 
teratur berolahraga maka tidak mengalami kehilangan fungsi yang sama dengan lansia yang tidak aktif berolahraga (Potter \& Perry, 2009). Daya tahan sistem musculoskeletal, kelenturan dan kekuatan otot pada lansia secara umum mengalami penurunan namun pada lansia yang aktif menggerakkan tubuhnya tidak terjadi demikian, hanya saja, dengan kondisi yang terjadi terhadap perubahan dengan sendirinya lansia mengurangi aktivitas fisik.

Penurunan sistem musculoskeletal yang terjadi pada lansia dapat mempengaruhi penyakit-penyakit seperti osteoatritis, reumatik, dan penyakit yang menggangu sistem muskuloskeletal lainnya (Fatmah, 2010). Pada lansia mengalami penurunan elastisitas dan daya lentur pada jaringan ikat sekitar sendi seperti fasia, ligament, kartilago, tendon dan jaringan periartikular (Adam, 1978). enurunan gerak sendi terjadi bila sendi mengalami kehilangan fleksibilitasnya, yang berdampak pada kekakuan sendi, bengkak, gangguan jalan, nyeri, adanya keterbatasan luas gerak sendi dan aktivitas keseharian lainnya. Teknik perlindungan sendi dalam beraktivitas merupakan upaya mencegah kerusakan sendi (Pudjiastuti \& Utomo, 2002).

Nyeri merupakan suatu kondisi yang lebih dari sekedar sensasi tunggul yang disebabkan oleh stimulus tertentu. Sifat nyeri adalah subjektif dan sangat individual. Tujuan mekanisme fisiologis nyeri adalah untuk melindungi diri. Perilaku akan berubah bila seseorang mengalami nyeri. Adanya kerusakan jaringan yang terjadi merupakan tanda adanya nyeri sehingga saat menkaji nyeri harus menjadi petimbangan utama dalam keperawatan (Potter \& Perry, 2006).

Penyebab ketidakmampuan mengarah ke nyeri. Banyaknya orang mengalami penyakit kronis, peningkatan usia harapan hidup dan nyeri merupakan gejala umum. Proses penuaan yang tidak dapat dihindari bukan bagian dari nyeri. Proses pengkajian, diagnose dan penatalaksanaan secara agresif perlu dilakukan pada lansia yang mengalami nyeri. Pada lansia beresiko tinggi mengalami situasi nyeri. Kondisi patologis yang menyertai nyeri kemungkinan lebih tinggi dialami lansia hidup lebih lama.

Aktifitas fisik merupakan pergerakan tubuh yang berdampak pada pengeluaran tenaga yang bertujuan pemeliharaan kesehatan baik secara mental maupun fisik dan pertahanan kualitas hidup agar lebih sehat dan bugar sepanjang hari. Dengan melakukan aktifitas fisik, maka lansia tersebut dapat mempertahankan bahkan meningkatkan derajat kesehatannya. Sejak tahun 1980, Amerika melakukan upaya untuk menurunkan angka keterbatasan untuk malakukan aktifitas fisik dasar dan berhasil meningkatkan presentase lansia yang bebas dari keterbatasan untuk malakukan aktifitas fisik dasar atau mampu beraktifitas fisik dasar (Fatmah, 2010).

Ada beberapa alasan penting mengapa aktifitas fisik bisa menjaga kondisi tubuh tetap sehat. Diantaranya adalah meningkatkan kelenturan otot serta menguatkan dan memperpanjang daya tahan otot. Aktifitas yang banyak menggunakan otot langan dan otot paha disebut aerobic, 
akan membuat kerja jantung lebih efesien, baik saat olahraga maupun saat istirahat. Aktifitas seperti jalan cepat, lompat tali, jogging, bersepeda, gerak jalan (hiking), atau dansa adalah contoh aktifitas aerobic yang bermanfaat sebagai peningkatan daya tahan fisik (Fatmah, 2010).

Latihan fisik segala upaya yang dilaksakan untuk meningkatkan kebugaran jasmani dan kondisi fisik lansia. Stretching merupakan aktivitas peregangan otot yang bertujuan untuk jangkauan gerakan persendian dan peningkatan fleksibilitas pada otot. The Crossfit Journal Article (2016) mengemukakan bahwa untuk meningkatkan fleksibilitas otot dan sendi, stretching sangat efektif dilakukan karena dapat memberikan efek penurunan nyeri persendian. Latihan aktivitas fisik (stretching) dapat meningkatkan aliran darah dan memperkuat tulang (Rahmiati, 2017), Sejalan dengan penelitian dengan judul The Effectiveness of Hip and Knee Strengthening on Reducing Pain Intensity among Elderly with Osteoarthritis dengan hasil bahwa pemberian intervensi Strengthening efektif dapat mengurangi intensitas nyeri (Marlina \& Sr Lucilla, 2019). Setiap jenis latihan fisik sebaiknya dilaksankan melalui tahap pemanasan, latihan inti, dan pendinginan. Pemanasan bertujuan untuk memberkan stimulasi awal pada tahap latihan agar bersemangat. Pemanasan harus meliputi 2 komponen, yaitu yang pertama latihan aerobic yang bertahap dan yang kedua latihan kelenturan (fleksibility) sesuai dengan aktifitas yang dilakukan.

Setiap jenis latihan fisik sebaiknya dilaksankan melalui tahap pemanasan, latihan inti, dan pendinginan. Pemanasan bertujuan untuk memberi dorongan hasrat latihan agar bersemangat. Pemanasan harus meliputi 2 komponen, yaitu yang pertama latihan aerobic yang bertahap dan yang kedua latihan kelenturan (fleksibility) sesuai dengan aktifitas yang dilakukan. Ketergantungan gerakan inti bertumpu pada sasaran latihan yang harapkan untuk peningkatan kekuatan otot lebih cocok ke anaerobic, dan untuk peningkatan kelenturan sendi yaitu dengan rileksasi serta ketangkasan maupun keterampilan lebih cocok dengan senam. Pendinginan dan pemanasan sama sama penting. Sehingga pada setiap akhir latihan fisik harus dilakukan pendinginan (Pudjiastuti \& Utomo, 2002). Untuk dosis latihan meliputi pengaturan frekuensi (frequencie), itensitas (itencity), durasi (time), dan macam (type latihan). Untuk frekuensi dialakukan tiga atau lima kali dalam tiap minggunya. Itensitas didasarkan atas beban latihan dan merupakan faktor yang penting dalam program latihan (Pudjiastuti \& Utomo, 2002).

Latihan Aktifitas fisik (Stretching) tidak hanya membantu lansia yang mengalami nyeri sendi saja namun pada penderita Low Back Pain pun dapat membantu menurunkan nyeri seperti yang dilakukan penelitian oleh (Afia \& Oktaria, 2018) dengan hasil penelitian bahwa ada pengaruh Stretching Terhadap Pekerja yang Menderita Low Back Pain. Latihan streching dapat meningkatkan kekuatan otot tungkai bawah, lumbal, lutut lansia menjadi fleksibilitas serta menambah kemampuan berdiri pada satu kaki. Tujuan Stretching atau peregangan yaitu untuk 
menjaga elastisitas otot dan memanjangkan struktur jaringan lunak yang memendek baik patologis maupun non patologis sehingga lansia dapat meningkatkan aktifitas geraknya. Nyeri punggung bawah, nyeri sendi lutut dan nyeri pergelangan kaki dapat dilakukan salah satu terapinya adalah dengan latihan peregangan (Sunarto, 2005).

Hasil penelitian yang dilakukan oleh (Monayo \& Akuba, 2019) ada pengaruh stretching exercise terhadap penurunan skala nyeri pada pasien yang mengalami nyeri sendi lutut Osteoartritis dengan p-value $(0,000)<\alpha(0,05)$. Berdasarkan hasil penelitian-penelitian tersebut maka diperlukan peran perawat sebagai pendidik untuk memberikan pendidikan kesehatan mengenai latihan aktivitas fisik (stretching). Hal tersubut didukung oleh penelitian (Yanti, Widyanthari, Kusumaningsih, \& Astuti, 2016) bahwa Upaya pencegahan yang dapat dilakukan dengan strategi promosi kesehatan berupa penyuluhan kesehatan nyeri sendi. Kegiatan ini dilaksanakan $80 \%$ dari jumlah total lansia sangat antusias mengikuti kegiatan penyuluhan.

\section{BAHAN DAN METODE}

Rancangan penelitian merupakan rancangan penelitian yang digunakan untuk menuntun peneliti memperoleh jawaban terhadap penelitian dengan mengacu pada jenis penelitian yang digunakan. Dalam penelitian ini, peneliti menggunakan desain penelitian Quasy Experiment dengan pendekatan One Group Pretest Postest. Dalam rancangan ini, tanpa ada kelompok kontrol, namun sudah dilakukan observasi pertama (Notoatmodjo, 2012). Populasinya adalah lansia yang mempunyai keluhan nyeri sendi di Desa Megucilik - Cirebon. Sampelnya adalah lansia dengan nyeri sendi di desa Megucilik-Cirebon sebanyak 30 orang. Teknik pengambilan sampel pada penelitian ini menggunakan Total Sampling yaitu jumlah sempel yang diambil sama dengan jumlah populasi. Instrumen penelitian untuk mengumpulkan data, dimana peneliti melaporkan keterangan penelitian baik secara tertulis maupun lisan dari responden yang akan diteliti. Instrumen yang digunakan pada penelitian ini adalah instrument yang berisi skala nyeri numerik atau The Pain Numerical Rating Scale (PNRS) dan observasi.

\section{HASIL DAN PEMBAHASAN}

\section{Intensitas Nyeri Sebelum dan Sesudah Latihan Aktifitas Fisik (Stretching)}

Sebelum latihan aktifitas fisik (stretching) dilakukan, responden diminta untuk menunjukkan skala nyeri yang dirasakan. Berdasarkan pengukuran nyeri yang dilakukan sebelum terapi, sebagian besar responden menunjukkan nyeri pada rentang $4-6$ (sedang) yaitu sebanyak 22 orang $(73.3 \%)(\mathrm{M}=3.00, \mathrm{SD}=0.525)$. Sedangkan sesudah latihan aktifitas fisik (stretching), 
nyeri yang di timbulkan oleh responden berkurang skalanya sehingga nyeri pada rentang 1 - 3 (ringan) yaitu sebanyak 26 orang $(86.7 \%)(\mathrm{M}=2.17, \mathrm{SD}=0.461)$. Hasil pengukuran intensitas nyeri sebelum latihan aktifitas fisik (stretching) dan sesudah latihan aktifitas fisik (stretching) lebih lengkap dapat dilihat pada tabel 1. Dibawah ini:

Tabel 1. Hasil Pengukuran Intensitas Nyeri Sebelum dan Sesudah Latihan Aktifitas Fisik (Stretching)

\begin{tabular}{lcclcc}
\hline \multicolumn{3}{c}{$\begin{array}{r}\text { Sebelum Latihan Aktifitas Fisik } \\
\text { (Stretching) }\end{array}$} & \multicolumn{3}{c}{$\begin{array}{c}\text { Sesudah Latihan Aktifitas Fisik } \\
\text { (Stretching) }\end{array}$} \\
\hline Intensitas Nyeri & $\begin{array}{c}\text { Frekuensi } \\
\text { (n) }\end{array}$ & $\begin{array}{c}\text { Persentase } \\
(\%)\end{array}$ & Intensitas Nyeri & $\begin{array}{c}\text { Frekuensi } \\
(\mathrm{n})\end{array}$ & $\begin{array}{c}\text { Persentase } \\
(\%)\end{array}$ \\
\hline Tidak Nyeri (0) & 0 & 0 & Tidak Nyeri (0) & 0 & 0 \\
Ringan (1-3) & 4 & 13.3 & Ringan (1-3) & 26 & 86.7 \\
Sedang (4-6) & 22 & 73.3 & Sedang (4-6) & 3 & 10.0 \\
Berat (7-9) & 4 & 13.3 & Berat (7-9) & 1 & 3.3 \\
Berat Sekali (10) & 0 & 0 & Berat Sekali (10) & 0 & 0 \\
\cline { 2 - 3 } & $(\mathrm{M}=3.00, \mathrm{SD}=0.525)$ & & \multicolumn{2}{c}{$(\mathrm{M}=2.17, \mathrm{SD}=0.461)$} \\
\hline
\end{tabular}

Sumber: Data Primer, 2019

Dari hasil observasi yang dilakukan diperoleh bahwa intensitas nyeri yang dirasakan pasien menurun sesudah latihan aktifitas fisik (stretching) diberikan. Secara kuantitatif menunjukkan ada perubahan positif atau penurunan positif intensitas nyeri setelah dilakukan latihan aktifitas fisik dibanding sebelum dilakukan. Sebelum latihan aktifitas fisik sebagian besar responden menunjukkan nyeri pada rentang 4-6 (sedang) yaitu sebanyak 22 orang (73.3\%), nyeri pada rentang 1-3 (ringan) sebanyak 4 orang (13.3\%) dan nyeri pada rentang 7-9 (berat) sebanyak 4 orang (13.3\%). Sesudah latihan aktifitas fisik (stretching) diberikan bahwa responden menunjukkan nyeri pada rentang 1-3 (ringan) sebanyak 26 orang (86.7\%).

Jumlah responden ini bertambah jika dibandingkan dengan pengukuran yang dilakukan sebelum latihan aktifitas fisik (stretching) diberikan. Jumlah responden yang menunjukkan intensitas nyeri pada rentang 4-6 (sedang) adalah 3 orang (10.0\%) dan responden yang menunjukkan intensitas nyeri pada rentang 7-9 (berat) menjadi 1 orang (3.3\%). Sehingga jumlah responden yang menunjukkan nyeri pada rentang 7-9 (berat) berkurang.

Latihan aktifitas fisik (stretching) bertujuan untuk menurunkan intensitas nyeri yang dirasakan pasien. Karena latihan aktifitas fisik (stretching) adalah teknik untuk mengurangi ketegangan otot skeletal dan menurunkan kecemasan. Kecemasan dapat meningkatkan persepsi 
seseorang terhadap nyeri yang dirasakan. Hal ini merupakan hubungan timbal balik yang dapat dialami penderita nyeri. Bayangan akan rasa nyeri yang hebat tentu saja membuat cemas, namun metode yang sangat efektif untuk menurunkan nyeri yang kronis yautu dengan relaksasi (Irdawati, 2008). Hasil penelitian yang dilakukan oleh (Pamungkas, Hartati, \& Supriyono, 2016) adalah pemberian stretching efektif terhadap penurunan pada lansia yang mengalami nyeri sendi, sehingga latihan stretching dapat dijadikan intervensi mandiri terhadap nyeri sendi pada lansia

\section{Perbedaan Intensitas Nyeri Sebelum dan Sesudah Latihan Aktifitas Fisik (Stretching)}

Adapun untuk mengetahui ada tidaknya perbedaan atau pengaruh antara sebelum latihan aktifitas fisik (stretching) dan sesudah latihan aktifitas fisik (stretching) terhadap nyeri sendi pada lansia dilakukan uji statistik dengan menggunakan paired t-test. Dimana hasil rata-rata paired t-test ini adalah 0.833 dan Standar deviasinya 0.379. Hasil ini menunjukkan bahwa nilai $\mathrm{p}<0.05$ (0.000) yang artinya ada pengaruh latihan aktifitas fisik (stretching) terhadap lansia yang mengalami nyeri sendi atau ada perbedaan nyeri sendi antara sebelum latihan aktifitas fisik (stretching) dan sesudah latihan aktifitas fisik (stretching) dimana dapat dilihat pada tabel 2. dibawah ini.

Tabel 2. Hasil Uji Paired t-test untuk Intensitas Nyeri Sebelum dan Sesudah Latihan Aktifitas Fisik (Stretching)

\begin{tabular}{|c|c|c|c|c|c|c|c|c|}
\hline & \multicolumn{5}{|c|}{ Paired Difference } & & & \\
\hline & \multicolumn{8}{|c|}{$\begin{array}{c}\text { 95\% Confidence } \\
\text { Interval of the } \\
\text { Difference }\end{array}$} \\
\hline & Mean & $\begin{array}{c}\text { Std. } \\
\text { Deviation }\end{array}$ & $\begin{array}{c}\text { Std. Error } \\
\text { Mean }\end{array}$ & Lower & Upper & $\mathbf{t}$ & df & $\begin{array}{c}\text { Sig. } \\
(2-\text { tailed })\end{array}$ \\
\hline \multicolumn{8}{|l|}{ Sebelum } & \\
\hline $\begin{array}{l}\text { Sesudah } \\
\text { Latihan }\end{array}$ & .833 & .379 & .069 & .692 & .975 & $\begin{array}{c}12.0 \\
42\end{array}$ & 29 & .000 \\
\hline \multicolumn{9}{|l|}{ Aktifitas } \\
\hline Fisik & & & & & & & & \\
\hline
\end{tabular}


Demikian juga dari hasil nilai t hitung (12.042) menunjukkan lebih besar dari t tabel dengan df $=29$ ( 2.045), artinya bahwa Ho ditolak atau Ha diterima yaitu ada pengaruh latihan aktifitas fisik ( stretching) terhadap nyeri sendi, atau ada perbedaan nyeri sendi antara sebelum latihan aktifitas fisik ( stretching) dan sesudah latihan aktifitas fisik.

\section{Pengaruh Latihan Aktifitas Fisik (Stretching) Terhadap Intensitas Nyeri Sendi pada}

\section{Lansia}

Dari hasil penelitian yang telah dilakukan diperoleh bahwa intensitas nyeri yang dirasakan pasien menurun sesudah latihan aktifitas fisik (stretching) diberikan. Penurunan nyeri ini diperoleh dari pengukuran nyeri sebelum dan sesudah latihan aktifitas fisik (stretching) dengan menggunakan uji paired t-test. Hasil rata-rata uji paired t-test ini adalah 0.833 dan Standar deviasinya 0.379. Hasil ini menunjukkan bahwa nilai $\mathrm{p}<0.05(0.000)$ yang artinya ada pengaruh yang signifikan/bermakna. Maka dari hasil uji paired t-test tersebut diketahui bahwa ada pengaruh latihan aktifitas fisik (stretching) terhadap penurunan intensitas nyeri.

Penelitian ini berkaitan dengan hasil penelitian dari Yohana Pamungkas yang didapatkan data sebelum dilakukan latihan aktivitas kaki (stretching) terdapat 7 responden (20\%) mengalami nyeri ringan, 20 responden $(51 \%)$ nyeri sedang, dan 9 responden $(22,9 \%)$ nyeri berat. Setelah dilakukan latihan aktivitas kaki (stretching) sejumlah 33 responden pada sendi ektremitas bawah mengalami penurunan nyeri. Dan seperti pada jurnal stretching dilakukan 3x selama 2 minggu dan didapatkan hasil skala nyeri sendi mengalami penurunan dan implementasi yang telah dilakukan peneliti selama 5 hari dalam satu minggu juga didapatkan hasil yang sama dengan jurnal yaitu skala nyeri sendi mengalami penurunan jika implementasi dilakukan secara teratur seperti pada jurnal atau setiap minggunya akan didapatkan hasil yang lebih signifikan dan bisa menjala skala atau intensitas nyeri pada lansia.

Terapi latihan stretching (peregangan) sangat bermanfaat, tidak hanya menurunkan nyeri saja namun dapat membantu memulihkan otot - otot yang kaku menjadi lentur. Manfaat Stretching atau peregangan adalah melatih otot, pelebaran kapiler otot sehingga tercapai derajat panjang dan fleksibilitas normal, sirkulasi darah membaik, dan sampah metabolisme berkurang serta peningkatan supply oksigen pada sel otot akan mengurangi nyeri (Anderson, 2008) Setelah melakukan manajemen nyeri dengan aplikasi latihan gerak stretching responden merasa lebih tenang dan rileks serta skala nyeri yang dirasakan berkurang.

Penelitian yang dilakukan oleh (Poernomo \& Pamungkas, 2010) bahwa ada pengaruh latihan aktifitas fisik (stretching) yang mengalami nyeri sendi ekstremitas bawah pada lansia mengalami penurunan. Hasil penelitiannya adalah responden mengalami nyeri sedang sebanyak 
57\% sebelum diberikan stretching dan 94,2\% responden mengalami penurunan nyeri sendi ekstremitas bawah setelah dilakukan stretching (Poernomo \& Pamungkas, 2010). Kemudian (Sa'adah, 2012), juga melakukan penelitian yang hasilnya menunjukkan bahwa terdapat pengaruh stretching dalam menurunkan nyeri punggung bawah terhadap lansia ( $\mathrm{p}$ value $=0,000$ dan nilai signifikan $₫ 0,05$ ).

Kedua penelitian ini menunjukkan adanya pengaruh latihan stretching dalam menurunkan nyeri sendi pada lansia. Hal ini dikarenakan setelah lansia diberikan stretching dengan benar dan teratur, otot-otot yang tegang akan berkurang dan mempertahankan atau meningkatkan kelenturan tubuh sehingga tubuh terasa lebih relaks. Selain itu juga rentang gerak lansia menjadi lebih luas sehingga membuat aktivitas yang berat menjadi lebih mudah dilakukan. Dengan adanya penurunan rasa nyeri sendi lutut yang merupakan salah satu sendi penahan beban tubuh yang besar, maka lansia dapat menjadi lebih aktif, produktif dan dapat menjalani masa tuanya dengan lebih nyaman.

\section{KESIMPULAN DAN SARAN}

Berdasarkan hasil analisa dan pembahasan tentang pengaruh latihan aktifitas fisik (stretching) terhadap nyeri sendi pada lansia di Desa Megucilik Kecamatan Weru Kabupaten Cirebon yang dilakukan pada 30 responden, dapat disimpulkan bahwa sebelum dilakukan latihan aktifitas fisik ( stretching), intensitas nyeri sendi sebagian besar responden menunjukkan nyeri sedang. Namun sesudah dilakukan latihan aktifitas fisik (stretching), intensitas nyeri sendi yang dirasakan oleh responden sebagian besar berkurang menjadi nyeri ringan. Ada perbedaan atau pengaruh antara sebelum dan sesudah dilakukan latihan aktifitas fisik ( stretching ) terhadap nyeri sendi pada lansia. Dengan kata lain ada pengaruh latihan aktifitas fisik ( stretching ) terhadap penurunan nyeri sendi pada lansia.

Hasil penelitian ini diharapkan dapat memberikan informasi yang baru dalam penekanan materi terutama sebagai latihan aktifitas fisik (stretching) dalam dunia pendidikan keperawatan. Selain itu, dengan ditemukannya pengaruh latihan aktifitas fisik (stretching) terhadap nyeri sendi, diharapkan perawat dapat menjadi motivator dan fasilitator bagi pasien lansia dengan nyeri sendi demi membantu menurunkan nyeri yang dirasakan pasien tersebut. Hasil penelitian ini juga diharapkan membantu penyelesaian masalah keperawatan nyeri sendi pada lansia dan pelaksanaan dapat berjalan sesuai dengan prosedur pelaksanaan. Melalui hasil penelitian ini, diharapkan juga kepada lansia agar terus melakukan latihan fisik dan mempelajari dan 
menghafalkan gerakan yang sesuai yang telah di ajarkan instruktur agar dapat mempertahankan aktivitas tubuh yang baik

\section{UCAPAN TERIMA KASIH}

Ucapan terima kasih penulis haturkan kepada seluruh masyarakat lansia di Desa Megucilik Kecamatan Weru Kabupaten Cirebon, yang telah terlibat dalam penyelesaian kegiatan pengabdian Penyuluhan Kesehatan Tentang Latihan Aktivitas Fisik (Stretching) Terhadap Nyeri Sendi Pada Lansia Di Desa Megucilik Kabupaten Cirebon.

\section{DAFTAR PUSTAKA}

Adam, G. F. (1978). Essentials Of Geriatric Medicine. New York Toronto: Oxford University.

Afia, F. N., \& Oktaria, D. (2018). Pengaruh Stretching Terhadap Pekerja yang MenderitaLow Back Pain. Jurnal Agromedicine, 5(1).

Anderson, B. (2008). Stretching (Peregangan). Jakarta: PT. Serambi Ilmu Semesta.

Badan Pusat Statistik. (2010). Statistik Kependudukan Indonesia. Retrieved from http://jabar.bps.go.id/ linkTabelStatis/view/id/15

Darmojo, B., \& Martono, H. H. (2006). Geriatri (Ilmu Kesehatan Usila) Edisi 5. Jakarta: FK Universitas Indonesia.

Fatmah. (2010). Gizi Usia Lanjut. Jakarta: Erlangga.

Irdawati. (2008). Perbedaan Pengaruh Latihan Gerak Terhadap Kekuatan Otot Pada Pasien Stroke Non-Hemoragik Hemiparese Kanan Dibandingkan Dengan Hemiparese Kiri. Surakarta: Media Medika Indonesia.

Marlina, T. T., \& Sr Lucilla, H. (2019). The Effectiveness of Hip and Knee Strengthening on Reducing Pain Intensity among Elderly with Osteoarthriti. In the ICHT Committee Conference paper.

Monayo, E. R., \& Akuba, F. (2019). Pengaruh Stretching Exercise Terhadap Penurunan Skala Nyeri Sendi Lutut Pada Pasien Osteoartrtis. Jambura Nursing Journal, 1(1).

Pamungkas, Y. I., Hartati, E., \& Supriyono, M. (2016). Efektifitas pemberian stretching terhadap penurunan skala nyeri sendi pada lansia di unit pelayanan sosial lanjut usia wening wardoyo ungaran. Jurnal STIKes Telogorejo, 5.

Poernomo, D. I. S. H., \& Pamungkas, Y. (2010). Pengaruh latihan gerak kaki (stretching) terhadap penurunan nyeri sendi ekstremitas bawah pada Lansia di Posyandu Lansia Sejahtera GBI Setia bakti Kediri. Jurnal Penelitian Stikes RS Brapti SKediri, 3(1). 
Potter, \& Perry. (2006). Fundamental Of Nursing. Jakarta: ECG.

Potter, \& Perry. (2009). Fundamental Of Nursing Edisi 7. Jakarta: Salemba Medika.

Pudjiastuti, S. S., \& Utomo, B. (2002). Fisioterapi Pada Lansia. Jakarta: ECG.

Rahmiati. (2017). Efektivitas Stretching terhadap Penurunan Nyeri sendi lutut Pada Lansia di UPTD Rumoh Seujahtera Geunaseh Sayang Banda Aceh. Jurnal Ilmu Keperawatan.

Sa'adah, H. D. (2012). Pengaruh latihan Fleksi William (Stretching) terhadap tingkat nyeri punggung bawah pada lansia di Posyandu Lansia RW 2 Desa Kedungkandang Malang. Jurnal STIKES NU Tuban, 5(2).

Sunarto. (2005). Latihan pada penderita punggung bawah.

Yanti, N. L. P. ., Widyanthari, D. ., Kusumaningsih, F. ., \& Astuti, I. . (2016). penyuluhan latihan gerak sendi untuk mengurangi nyeri sendi pada lansia di desa dauh puri kauh dan desa kesiman kertalangu. Jurnal Udayana Mengabdi, 15(3). 